Clinical Image

\section{COVID-19 Associated acute limb}

\section{ischemia}

\section{Yogendra Mishra*, Satish Kumar and Meghna K}

Armed Forces Medical College, Pune, India

A 78-year-old man, known case of, diabetes mellitus, and hypertension presented with fever, dry cough and dyspnea of five-day duration. He tested positive for SARS-CoV-2 infection and was admitted to the intensive care unit as a case of severe COVID -19 pneumonia. Evaluation revealed raised inflammatory markers CRP: $92.2 \mathrm{mg} / \mathrm{ml}$, LDH: $556 \mathrm{IU} / \mathrm{L}$, Ferritin: $286 \mathrm{ng} / \mathrm{ml}$, D-dimer: $3716 \mathrm{ng} / \mathrm{ml}$. On day 9 of illness, he developed numbness, pain and discoloration of right hand. Physical examination was consistent with Acute Limb Ischemia (Rutherford Class III) right hand with absent radial and ulnar pulses. Color Doppler Flow Imaging of the right upper limb revealed absent right ulnar and radial arterial flow. He was planned for catheter-directed thrombolysis with thrombectomy. However, he developed ARDS with Acute Kidney Injury and was started on mechanical ventilation and renal replacement therapy. Unfortunately, he succumbed to his illness. The case summarizes thrombotic complication of COVID-19, which requires early recognition in patients with very high $\mathrm{D}$-dimer levels and treatment to prevent adverse outcomes.

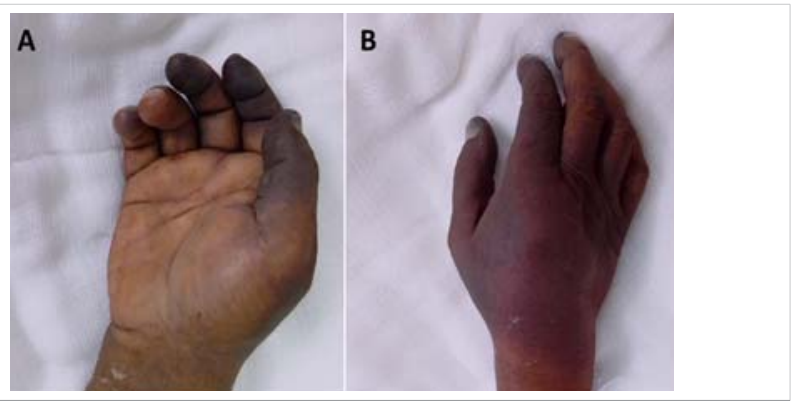

More Information

*Address for Correspondence:

Dr. Yogendra Mishra, Armed Forces Medical College, Pune, India,

Email: yogendrasunny@gmail.com

Submitted: July 14, 2021

Approved: July 19, 2021

Published: July 20, 2021

How to cite this article: Mishra Y, Kumar S, Meghna K. COVID-19 Associated acute limb ischemia. J Clin Med Exp Images. 2021; 5: 005-005.

DOI: 10.29328/journal.jcmei.1001021

Copyright: @ 2021 Mishra Y, et al. This is an open access article distributed under the Creative Commons Attribution License, which permits unrestricted use, distribution, and reproduction in any medium, provided the original work is properly cited.

Check for updates

Open Access 